\title{
Daunorubicin Citrate
}

National Cancer Institute

\section{Source}

National Cancer Institute. Daunorubicin Citrate. NCI Thesaurus. Code C47471.

A semi-synthetic anthracycline glycoside antibiotic obtained from Streptomyces with antineoplastic activity. Daunorubicin citrate intercalates DNA, which leads to inhibition of DNA and RNA synthesis, and consequently blocks cell division and results in apoptosis. This anti-tumor antibiotic is most active in the $\mathrm{S}$ phase of cell division. Daunorubicin is indicated in the treatment of a wide variety of cancers including acute non-lymphocytic leukemia, non-Hodgkin lymphomas, Ewing's sarcoma, Wilms' tumor, and chronic myelocytic leukemia. ( $\mathrm{NCl05)}$ 